\title{
Multimodal College English Class with Ecology Orientation
}

\author{
Wang Wenhua \\ School of Foreign Languages, Xi'an Shiyou University \\ Xi'an China \\ e-mail: wangwenhua@xsyu.edu.cn
}

\begin{abstract}
A new mode of college English classroom is designed from the perspective of the ecology of education in order to solve the problem of inefficient class teaching. Empirical study shows that the class mode can improve students' interest in English, stimulate students' language learning channels, and considerably cultivate students in their English listening, speaking, and writing abilities, thus achieving the ultimate goal of English Language application level.
\end{abstract}

Keywords-Ecology of Education; Multimodal Class; English Learning

\section{INTRODUCTION}

For a long time, experts think that English practical competence of Chinese students couldn't meet the needs of the society, especially for listening and speaking. English teachers are beset by this problem for many years, and it is discussed and agreed universally that the language learning environment and inadequate language material input all together are the main causes. With the internet coming into the classes, it is helpful for teachers to improve English teaching, strengthen its effects and further improve student's English competence in all aspects, which are also the pressing needs of majority students. In our university, a new mode of improving the teaching effects of listening, speaking, reading and writing in a integrated way with the help of internet resources is tried and studied creatively, and the results of class practice is offered in the paper.

\section{LITERATURE REVIEW}

\section{A. Ecology of Education}

Ecology of education is a science to study the interaction and development of the education and its environment (including natural, social, normative and eco-physiological.) In 1920s, German scholars Busemann. A. and Popp. W. tried to establish a discipline of "Education Environment". They studied how education and its macro-environments, like social, urban and home environment and the like, affect the children's development and teaching activities. At the same period, German also studied the relationship among the education, environment, and human's development. In 30s, the study on school environment in Britain and America include: Wade.J.T. Middle School Measurement as part of the students Environment(1935) mainly about the assessment of school management, teacher, student, physical environment, teaching material, and method; In Japan, the scholar Hosotani Toshio wrote a book, the Art of Education Environment, talking about how natural environment, social environment and spiritual environment influence the education.

The term "Ecology" formally used in the study of teaching was in 1932, an American educationist, Waller.W. who posed the concept "ecology of classroom" in his book, The Sociology of Teaching. In 1966, the America scholar Ashby put forward the concept "ecology of higher education" in his book, The universities in Britain, Indian and Africa: The study of Higher Education Ecology. Centering on the theme of "adaption" he studied fruitfully the higher education of Britain, Indian and Africa effectively, from the perspective of ecology. He stated the extensive principle of ecology used in the colonial universities, that is to say, these universities experienced the 
process of "beginning" and "growth", like creatures. And his theory expands the space for the development of university.

In 1976 American educationist, Lawrance. A. Cremin firstly proposed the concept "Education Ecology" and stated it exclusively. He holds that "the concept of ecology is useful because it emphasizes the relationship". The method of the study of education ecology is to put the education institutions and its structure into connection, and the relation to sustain and influenced by the broader regional framework need to be considered. Charlene Spretnak is the representative of ecology postmodernism. He supported the idea of ecological world outlook, that is, world is a organic whole composed by the relation net and everything in reality is connected internally and all the individuals are connected by relations.

The work in china discussed the relation between education and Environment more early is The Introduction to Education written by Zhuang Zexuan in 1926 and is also the head starter about theoretical forms of educational ecology. Later on, the book, The Introduction to Education written by $\mathrm{Wu}$ Junsheng and Wang Xizheng in 1935, discussed "heredity and environment", "development and adaption" in two chapters and discussed the law of educational ecology preliminarily. Zhang Liyuan studies more systematically human ecology from children's physical and mental development in his book, Bio-Education(1943).

In 1960s, Taiwanese scholar, Fang Binlin firstly engaged in educational ecology study and wrote the book Ecological Environment and Education. He insisted that we should study the relation between various ecological environment and education and the system that affecting the education focusing on the ecological factors. After 1990s, three representative works are published successively about educational ecology. The first one is Educational Ecology written by Wu Dingfu and Zhu Wenwei in 1990, argued that the education system and ecological system should be united. In terms of the analysis of ecological structure and function of education, the study should start with the interaction between education and its surrounding environment, expand and establish a interlaced network system structure, taking the educational system as the chief axis, the ecological system of education as cross section, so that we can describe the principle intensively and revel its basic rule of ecology of education. This is regarded as the first book to introduce educational ecology in the mainland.

The second book is Ecology of Educational written by Fan Guorui, who made some breakthroughs based on the former scholars. He illustrated educational ecology not only in establishing subject system, but also from culture, population, resources and environment aspects and quoted numerous overseas research achievements, and he also compared these research results with comparative method. The Higher Theory of Education Ecology written by He Zubin, studied ecology capacity and regional development about higher education. All these works discussed the educational ecological relation from schools, the educational organization, and representing a breakthrough in the theoretical study in this field. Wu Linfu's book, The Management of Educational Ecology inspecting various activities and phenomena in daily educational management from ecology illustrate the body management, the environmental management, information management, classroom management and security management and so on from educational ecology system and listed many ecological educational management cases that integrated theory with practice.

What's more, many articles about this subject published in academic journals. For instance, The Construction and Cultivation of the Primary Education Ecology, written by Zhang Fuzhong who urged to set up educational ecology awareness, break through the narrow educational ideas, adjust school's layout, optimize the allocation of resources and fully realize the role of society. In 1960, Fang Binglin who wrote Ecological Environment and Education, started to study this area. From then on, Wu Dingfu, Fan Guorui, Wei Jing, Tian $\mathrm{Xu}$ and $\mathrm{Du}$ Juan etc, illustrated educational ecology from different aspects.

"Requirements for College English", issued by Higher Education Department of Ministry of Education in 2007, 
proposed some related requirements about foreign language teaching environmental "ecologicalization". However, in our country, the teaching research from the perspective of educational ecology is still in its infancy.

\section{B. Multimodal Teaching}

Multimodal discourse refers to a phenomenon that various senses, such as hearing, vision and touching etc are employed. And different methods, like language, picture, voice and action as well as sighs altogether are used to communicate with each other.

R. Barthes is one of the earliest researchers about multimodal discourse analysis. He discussed the interaction between images and languages in the sense of expression in his thesis. Rhetoric of the image, published in 1977. Kress. G. Vanleeuwen, T studied the relation between mode and media, including visual image, color grammar, layout design of newspaper and the functions of different medium.

In 1996, Guntherkress and Leeuwen pointed out that multimodal is a mode using several social signs simultaneously and a mode that people communicate with people or with machine under the corresponding medium. $\mathrm{Gu}$ Yueguo, in his book the Analysis of Multimedia and Multimodal Learning, pointed that mode is a way that people interact with external environment by their sense organs, single modal using one organ, double modals using two, three and more called multimodal. $\mathrm{Hu}$ Zhuanglin believed that modal is a sign system which can be contrasted and opposed. To feel the physical world, we can see, listen, touch, taste and smell, all of which are different perceptual modalities. In our life, people communicate with each other through different senses and teaching activities are naturally achieved through the interaction between students, teachers, textbooks and teaching materials, so teaching activities also require participation of different senses and multimodalities.

In 1996, New London Group proposed the concept of multimodal teaching method. It suggested that we should break with the traditional single modal teaching method, emphasizing on training learners' multiple abilities and promoting their interests in autonomous learning by using different channels, like media, pictures, roles and music and different teaching methods. In the process of learning, we should use multiple senses to work and study actively in the environment. In Stein's view, class teaching should contain multimodal symbol space, among which are visual model, written model, oral model, performing model, audio model and body model etc. Teachers should design various multimodal teaching tasks, so students can complete these tasks through multimodal methods. In 1980, Mueller found out that pictures can enhance students' memory and visual stimulus can strengthen their language understanding. Zhang DeLu and WangLu also supported that in multimodal discourse, different models worked together to realize the speaker's meaning.

The reform and practice of English multimodal teaching was based on the multimodal discourse analysis theory thrived in 1990s. It was proposed by Kress and Van Leeuwen, Stein put forward multimodal teaching method, insisting that the course, teaching and evaluation should be developed based on the modality of learning environment, and all communicative activities in class are multimodal. Linguists in our country, $\mathrm{Hu}$ ZhuangLin, Gu YueGuo, Zhu Yongsheng and Zhang Delu also laid solid foundation for introducing and studying the multimodal discourse analysis theory. They made great contributions to our country in this field. In recent years, as for multimodal English learning, Wang Chunlei has studied the theoretical basis of psychology and the channel of building learning model, as well as how to integrate multilevel interaction and multimodal. Li Xin studied how to conduct multimodal self-aided listening teaching more effectively. These studies focused on what influence different input mode will bring on the comprehension of second language and its subsidiary vocabulary learning. But the empirical research that combine the idea of ecology of education with multiple modal to teach English are very few till now.

\section{RESEARCH DESIGN}

\section{A. Research purpose}

To construct an ecological multimodal English class mode of "visual, reading, listening, speaking, writing" with the integration of traditional pattern and the advantage of modern network, realizing the cultivation of students' individual 
differences, learning strategies, emotional factors, and culture awareness, and study the assessment feasibility of teaching English listening, speaking, reading and writing by using internet and ecological multimodal method in university English class so as to improve the teaching effect..

\section{B. Ecological multimodal teaching mode}

With teachers as the organizer of the class and with the help of internet, the following steps are all accomplished mainly bu students.

The basic framework of the ecological multimodal teaching mode with internet is shown in the following figure 1 .

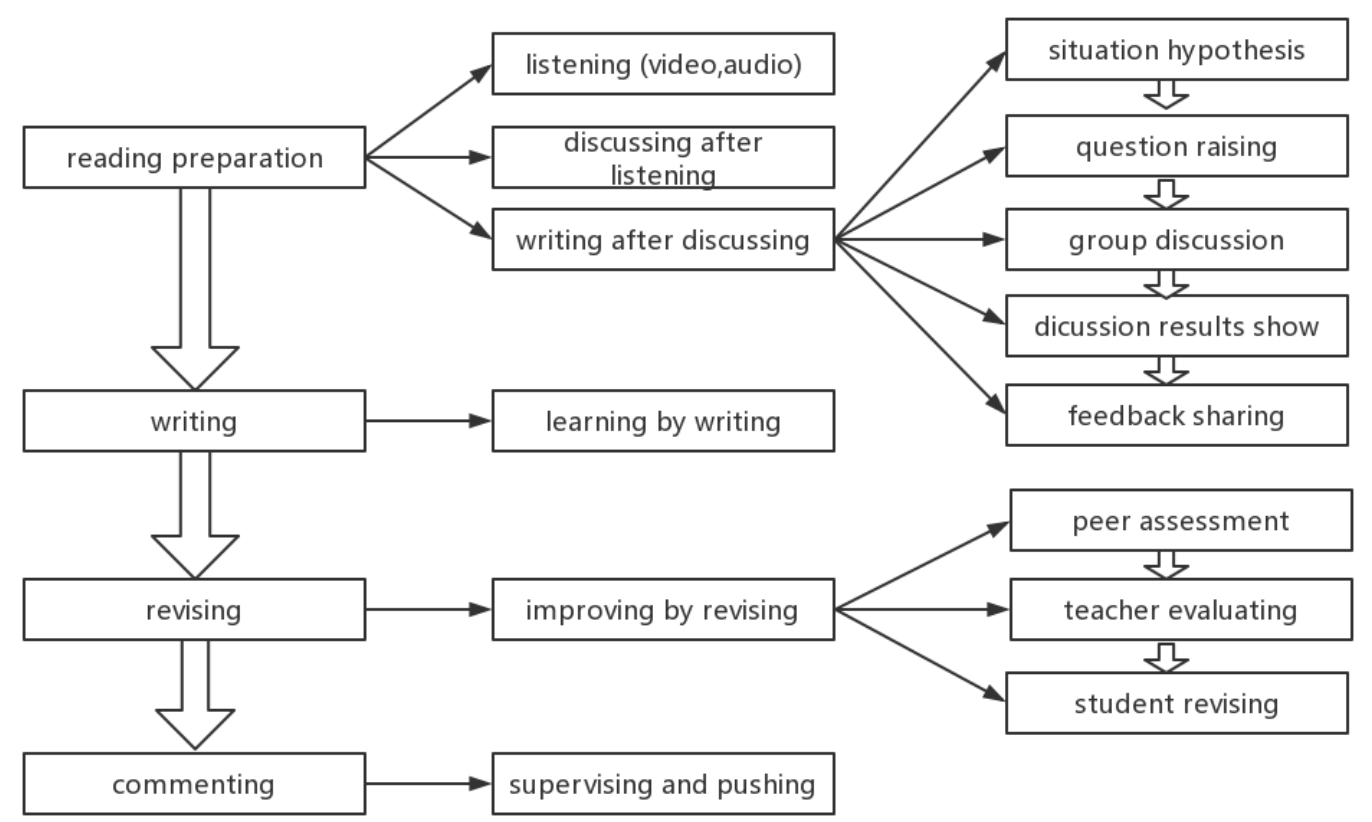

\section{Research subjects}

In September 2010, a total of 125 students from four natural classes of the petroleum engineering college randomly selected for the experimental class of xi 'an shiyou university. In these four classes, three semesters of English teaching of the design mode is practice. Then four classes of 120 students from the electronic engineering college are randomly selected as the control class. All the students passed the college entrance exam, and their English are almost at the same level. The teachers of control class adopted the traditional teaching method in the same period. The pretest and post-test results of listening, speaking and writing of the experimental class and control class are analyzed.

\section{Research tools}

In the experiment, we mainly used two kinds of research tools: the pretest and post-test of listening, speaking and writing of the experimental class and control class, and the questionnaire of the two group students.

Pretest: before the experiment, the experimental class and control class were are tested for their listening, speaking and writing with title of My favourite teacher, namely pretest, with time limit of 30 minutes, and the total score was 15 points

After the experiment, the experimental class and the control class were given a second listening, speaking and writing test, namely post- test, and the title was Our English class, and the time was 30 minutes, and the score was 15 points.

As for the marking of the tests, five criteria of speaking and writing test for college English Bang Four are used, namely: relevant content, sentence variety, text coherent, clear, language specification, on the basis of the students' dynamic performance of listening, speaking, and writing. The specific points and final scores of students depend on their performance of each situation, then SPSS15.0 software are used for statistical analysis. 
Questionnaire: 125 questionnaires were issued, 125 effective questionnaires were collected and $100 \%$ effective. LIKERT scale is used for the questionnaire, and all the problem is divided into: very don't agree with, don't agree, uncertain, and very agree with the five aspects, score from 1 to 5 , the higher the score indicate that the participants learns well in the ecological multimodal English class, and pays attention to the construction of ecological multimodal class.

\section{RESEARCH RESULTS}

The data of the pretest and post-test results are analyzed, and the results are shown in table 1 , table 2 and table 3 .

TABLE I. CONTRAST OF THE RESULTS OF LISTENING AND SPEAKING IN THE TWO TESTS

\begin{tabular}{|c|c|c|c|c|c|c|c|}
\hline & & \multirow[b]{2}{*}{ number } & \multirow[b]{2}{*}{ mean } & \multirow[b]{2}{*}{$\begin{array}{c}\text { deviatio } \\
\mathbf{n}\end{array}$} & \multirow{2}{*}{$\begin{array}{c}\text { Standar } \\
\text { d } \\
\text { deviatio } \\
\text { n }\end{array}$} & \multicolumn{2}{|r|}{$\mathbf{T}$} \\
\hline & & & & & & $T$ & $\begin{array}{c}\text { Probability } \\
\text { value }\end{array}$ \\
\hline \multirow[t]{2}{*}{ Test 1} & $\begin{array}{c}\text { Experimen } \\
t \\
\end{array}$ & 45 & 9.20 & \multirow[t]{2}{*}{0.04} & 5.70 & \multirow[t]{2}{*}{0.240} & \multirow[t]{2}{*}{0.76} \\
\hline & Control & 43 & 9.24 & & 5.68 & & \\
\hline \multirow[t]{2}{*}{ Test 2} & $\begin{array}{c}\text { Experimen } \\
t\end{array}$ & 45 & 12.62 & \multirow[t]{2}{*}{2.05} & 4.49 & \multirow[t]{2}{*}{2.673} & \multirow[t]{2}{*}{0.003} \\
\hline & control & 43 & 10.57 & & 5.80 & & \\
\hline
\end{tabular}

As can be seen from table 1, there are significant differences between the two groups of students on the level of $\mathrm{P}=0.003$. This shows that compared with the comparison group, the ecological multimodal teaching mode is superior to the traditional mode in improving the students' listening and listening level.

TABLE II. STATISTICS OF PRETEST AND POST-TEST SCORE

\begin{tabular}{|c|c|c|c|c|c|c|}
\hline & \multicolumn{3}{|c|}{ Experiment group } & \multicolumn{3}{c|}{ Control group } \\
\hline & average & $\begin{array}{c}\text { Standard } \\
\text { deviation }\end{array}$ & $\begin{array}{c}\text { Standard } \\
\text { mean error }\end{array}$ & average & $\begin{array}{c}\text { Standard } \\
\text { deviation }\end{array}$ & $\begin{array}{c}\text { Standard mean } \\
\text { error }\end{array}$ \\
\hline pretest & 5.8148 & 1.82306 & 0.24809 & 6.0185 & 1.86821 & 0.25423 \\
\hline $\begin{array}{c}\text { Post- } \\
\text { test }\end{array}$ & 8.2963 & 1.75510 & 0.23884 & 6.9074 & 2.02129 & 0.27506 \\
\hline
\end{tabular}

TABLE III. INDEPENDENT SAMPLE T TEST OF PRETEST AND POST-TEST SCORE

\begin{tabular}{|c|c|c|c|c|c|c|c|}
\hline & \multicolumn{2}{|c|}{ variance similar test } & \multicolumn{5}{c|}{ Equal mean t- test } \\
\cline { 2 - 8 } & $\begin{array}{c}\text { Variance } \\
\text { value }\end{array}$ & $\begin{array}{c}\text { Test } \\
\text { probability }\end{array}$ & $t$ & freedom & $\begin{array}{c}\text { Double tailed } \\
\text { test } \\
\text { Probability }\end{array}$ & $\begin{array}{c}\text { Mean } \\
\text { difference }\end{array}$ & $\begin{array}{c}\text { Standard } \\
\text { mean } \\
\text { error }\end{array}$ \\
\hline pretest & 0.373 & 0.542 & 0.573 & 106 & 0.568 & 0.20370 & 0.35522 \\
\hline Post- test & 1.264 & 0.263 & -3.813 & 106 & 0.000 & -1.38889 & 0.36428 \\
\hline
\end{tabular}


Table 2 and table 3 shows that the average score of the control class in the pretest is 6.0185, the experimental classes is 5.8148 , double tail probability value Sig is .568, and it is greater than 0.05 . so, there is no significant difference for the writing score of two classes in the pretest. There is almost no difference for the students' writing ability of the experiment and control class. In the post-test the average score of control class is 6.9074, while the experimental classes having 8.2963. The average score of experimental classes are significantly higher than control class, double tail Sig value of 0.000 . And double tailed test probability is less than 0.05 , so the results are statistically significant. Through the comparative analysis of results, multimodal teaching mode is better than the traditional mode in improving students' English learning.

Through the analysis of the questionnaire, the result also show that students like ecological multimodal teaching mode, and that this teaching mode can improve their interest in learning English, and it is of great help to improve their English listening, speaking, reading, writing ability.

\section{CONCLUSION}

In ecological multimodal teaching class, teaching materials are rich and colorful with text, audio and visual, animation, and also with man-machine interactive teaching. This can fully demonstrate the constructiveness learning theory advocated by the new idea of "learning centered", and student-centered are emphasized in every situation, encouraging students to exert the principal role of knowledge construction. Students' ability of autonomous learning are cultivated in English listening, speaking, reading and writing.

Studies have shown that ecological multimodal class emphasizes the complete transformation of the teachers' role, that is, from the traditional knowledge teaching to students' learning helper and promoter. All teachers do is to help students complete the construction of comprehensive knowledge of the meaning of English and the ability of successful learning. This study proposed the multimodal teaching mode to bring the cooperative win-win advantage of multimodal cognitive learning into full play. Thus, cross modal learning platform is created for students to improve their English listening, speaking, reading and writing, and students' various language learning channels are fully stimulated. Finally students' interest in English learning is improved and they may achieve their ultimate goal.

\section{REFERENCES}

[1] Fang Binglin. Ecological environment and education [M]. Taipei: Taiwan Weixin Publishing House, 1975.

[2] Wu Dingfu, Chu Wenwei. Ecology of Education [M]. Nanjing:Jiangsu Education Publishing House, 2000.

[3] Fan Guorui. Ecology of Education [M]. Beijing: Renmin Education Press, 2000.

[4] Wei Jing. Research on the construction of the individual ecological environment of foreign language learners in multimedia network environment $[\mathrm{J}]$. Technology Enhanced Foreign Language Education, 2010 (11):69-76.

[5] Tian Xu, Kang Xiaoyun. Enlightenment of ecological theory on efficient English teaching [J]. Jiaoyu Tansuo, 2012 (5) :51-52.

[6] Du Juan, Yu Yang. An exploration of the evaluation method of ecological English teaching efficiency based on characteristics [J]. Foreign Language Research, 2012 (5) :125-128.

[7] Kress, g. and Van Leeuwen, t. Multimodal Discourse [M]. London: Arnold, 2011

[8] Stein, P.Rethinking resources: Multimodal pedagogies in the ESL classroom [J]. TESOL QUARTERLY, 2000(34):333-336.

[9] Hu Zhuanglin. Multi-modal analysis of social semiotics [J], Foreign Language Research, 2003 (5) : 1-8.

[10] Gu Yueguo. Analysis of multimedia and multi-modal learning [J]. Technology Enhanced Foreign Language Education, 2007 (4) :3-12.

[11] Zhu Yongsheng. Theoretical basis and research methods of multi-modal discourse analysis [J]. Foreign Language Research, 2007 (5) :82-86.

[12] Zhang Delu, Li Yuxiang. Research on the coordination of multi-modal classroom discourse [J]. Foreign Language Teaching and Research, 2012 (1) :39-43.

[13] Wang Chunlei. Construction of multi-modal English learning mode [J].Teaching and Management, 2012 (10) :126-127.

[14] Li xin, Li Meiying, WangJiazi. Empirical research on the effectiveness of multi-modal autonomous listening teaching mode [J]. Journal of PLA University of Foreign Languages, 2012 (11) :59-64 